\title{
Concise Commentary: Don't Delay Identifying Delayed Gastric Emptying in Gastroparesis Patients
}

\author{
Thomas L. Abell ${ }^{1}$
}

Published online: 22 May 2020

(c) Springer Science+Business Media, LLC, part of Springer Nature 2020

In this issue of Digestive Diseases and Sciences, Navas et al. [1] examine gastroparesis patients from the perspective of the extent of delay in gastric emptying. On the basis of over 1300 solid-phase 4-h scintigraphic gastric emptying scans, patients were classified as mild, moderate, or severe based on the extent of delay of gastric emptying. Of the nearly 300 patients studied, over $50 \%$ had moderate to severe gastric emptying delay. The patient demographics were representative of what is frequently seen clinically (primarily female, with the mean age in the mid-40s, and symptom duration $>4$ years). Common medications included prokinetics, which have the potential to accelerate gastric emptying. Opiates (identified in about $25 \%$ of patients) were associated with further delaying gastric emptying. Patients with the greatest delay in gastric emptying had increased use of hospital in- and outpatient resources including emergency department visits. The authors concluded that patients with delayed gastric emptying, particularly severe delay, are disproportionate consumers of healthcare resources, recommending that steps be taken to identify and effectively treat this cohort.

A number of comments can be made about the work. The authors' hypotheses were generally fulfilled: The primary hypothesis was that gastric emptying might relate to symptom response and to adversely acting medications; the secondary hypothesis was that a more marked emptying delay might adversely impact quality of life and healthcare costs. These are important findings that may help direct the clinical care of patients with gastroparesis. Nevertheless, the study only included patients with delayed gastric emptying, as defined in the following. Since only about half of patients with gastroparesis symptoms have delayed gastric emptying [2], the lack of inclusion of patients with normal emptying

Thomas L. Abell

thomas.abell@louisville.edu

1 The Arthur M. Schoen, MD Chair in Gastroenterology, The University of Louisville, Louisville, KY, USA but identical symptoms may limit the clinical usefulness of some of the conclusions. A small point about the inclusion criteria for delayed emptying is that although delay is usually defined as $>10 \%$ retention of a standardized solid meal at $4 \mathrm{~h}$ and/or $>60 \%$ at $2 \mathrm{~h}$, the 2-h values were not used [3]. New published guidelines addressing GI tract scintigraphy further detail the importance and significance of these time points [4].

The inclusion of symptomatic patients without delayed gastric emptying could have facilitated additional comparisons regarding in- and outpatient hospital utilization data and identification of patients who were the highest utilizers of hospital-based services, comparing those that were delayed versus non-delayed. A related area is the identification of pyloric dysfunction in gastroparesis, particularly with patients who have delayed gastric emptying, identifying a subset with "obstructive gastroparesis." Not mentioned in this publication is how many patients underwent definitive pyloric therapies other than botulinum toxin injections, which was mentioned.

Overall, this publication contributes to the literature of gastroparesis and supports the need for more detailed analysis of presentation, management, and outcomes in patients with the symptoms of gastroparesis combined with delayed gastric emptying.

\section{References}

1. Navas CM, Wadas ED, Zbib NH, Crowell MD, Lacy, BE. Gastroparesis and severity of delayed gastric emptying: comparison of patient characteristics, treatments and medication adverse events. Dig Dis Sci. (Epub ahead of print). https://doi.org/10.1007/s1062 0-020-06258-7.

2. Pasricha PJ, Colvin R, Yates K, et al. Characteristics of patients with chronic unexplained nausea and vomiting and normal gastric emptying. Clin Gastroenterol Hepatol. 2011;9:567.e764-576. e764.

3. Abell TL, Camilleri M, Donohoe K, et al. Consensus recommendations for gastric emptying scintigraphy: a joint report 
of the American Neurogastroenterology and Motility Society and the Society of Nuclear Medicine. J Nucl Med Technol. 2008;36:44-54.

4. Maurer AH, Abell T, Bennett P, et al. Appropriate use criteria for gastrointestinal transit scintigraphy. $\mathrm{J} \mathrm{Nucl} \mathrm{Med.}$ 2020;61:11n-17n.
Publisher's Note Springer Nature remains neutral with regard to jurisdictional claims in published maps and institutional affiliations. 